Reseñas

Recensão crítica a Francisco García Gronzález (ed.).Vivir en soledad. Viudedad, soltería y abandono en el mundo rural (España y América Latina, siglos XVI-XXI), Madrid, Ibero Americana/ Vervuert, 2020, 518 páginas.

\title{
Carvalhal, Hélder
}

\author{
(iD) Hélder Carvalhal \\ helderfmcarvalhal@gmail.com \\ Centro Interdisciplinar de Historia, Culturas e \\ Sociedades, Universidade de Évora, Portugal
}

Cuadernos de $\mathrm{H}$ ideas

Universidad Nacional de La Plata, Argentina

ISSN: 2313-9048

Periodicidade: Anual

vol. 14, núm. 14, 2020

cuadernosdehideas@perio.unlp.edu.ar

Recepção: 10 Outubro 2020

Aprovação: 27 Outubro 2020

URL: http://portal.amelica.org/ameli/jatsRepo/31/311050017/

index.html

DOI: https://doi.org/10.24215/23139048e041

O volume editado por Francisco García González examina o tópico da solidão no mundo rural iberoamericano durante os últimos quinhentos anos. O tópico em causa é relativamente recente e constitui terreno fértil para abordagens sob diversos pontos de vista, fazendo uso de metodologias qualitativas e quantitativas. Não obstante, o objectivo do volume não passa por "medir" a solidão (p. 13). Através de um feixe variado de questões acerca das vivências em solidão, observadas num conjunto díspar de geografias, é debatida a resiliência dos que optam ou são forçados a viver desta maneira. De igual modo, testa-se a convenção de que os solitários - e, sobretudo, as solitárias - vivem necessariamente num contexto de pobreza e desamparo. A este respeito, note-se que a esmagadora maioria dos capítulos que compõem a obra tendem a perspectivar o tópico através de uma análise de género, não raras vezes combinando-a com análises do ponto de vista económico, demográfico, e espacial. Esta opção é, simultaneamente, a maior vantagem e, em alguns casos, a maior debilidade do volume. Desenvolver-se-ão tais considerações mais à frente. No imediato, atente-se aos seus conteúdos.

Para além da esclarecedora introdução da autoria do editor, este volume é composto por dezassete capítulos, cujos espaços de observação regionais se dividem entre as diversas comunidades autónomas espanholas e visões agregadoras do mesmo país (nove capítulos) e pelos diferentes casos nacionais da América Latina (os remanescentes oito). Enumere-se brevemente os seus objectivos. Hortensio Sobrado Correa 
examina a solidão na Galiza do Antigo Regime, dando conta que muito dificilmente os lares (households) unipessoais poderiam sobreviver do ponto de vista económico, em especial se fossem chefiados por mulheres, sendo tais situações remediadas pelo apoio familiar e/ou da vizinhança. Maria José Pérez Álvarez aborda a solidão feminina no noroeste peninsular moderno sob o ponto de vista das mentalidades, salientando a proeminência das disposições concelhias no controlo do quotidiano das solteiras e viúvas. O terceiro capítulo, de Patrícia Suárez Álvarez, estuda os lares femininos unipessoais para a ruralidade asturiana setecentista. Ainda que preliminarmente, a autora avança que a viuvez seria a principal razão para explicar uma maior predominância de lares unipessoais femininos, quando comparados com os masculinos.

Francisco José Alfaro Pérez, fazendo uso das fontes setecentistas da diocese de Zaragoza, indica que a solidão aragonesa acompanhava em grande medida o ritmo de crescimento económico. A solidão tendia a aumentar em períodos de crise, ao passo que se tornava estatisticamente insignificante em contextos de recuperação e/ou crescimento. José Pablo Blanco Carrasco, partindo do caso de estudo rural estremenho nos períodos moderno e contemporâneo, advoga a que viuvez feminina constitui uma realidade pouco frequente, situação comparável à realidade rural espanhola. Variáveis como a evolução do mercado matrimonial, o património pessoal das visadas, ou a solidariedade familiar faziam com que as potenciais viúvas não passassem muito tempo isoladas. Já no caso andaluz setecentista (capítulo de Jesús Manuel González Beltrán), a solidão tende a ser reduzida, sobretudo nas zonas costeiras, onde os mecanismos de solidariedade também funcionam no sentido de adicionar parentes e/ou criados aos lares unipessoais. Excepçóes a esta regra encontram-se por vezes nas denominadas "viúvas de vivos", onde a ausência prolongada do marido (noutros continentes) propicia a solidão prolongada da respectiva consorte. Viuvez de teor similar é estudada por Francisco Fajardo Spínola para as ilhas Canárias entre finais do século XVII e inícios de oitocentos. No caso, os expedientes de viuvez promovidos pelos juízes diocesanos para o dito período providenciam uma imagem de precariedade generalizada entre estas mulheres.

Cristina López Villanueva e Isabel Pujadas Rúbies analisam a evolução dos lares unipessoais para a totalidade do território espanhol na contemporaneidade. Importa realçar o claro aumento dos lares unipessoais no período que medeia entre 1973 e 2011, algo que pode ser explicado por três vectores: pelas características sócio-demográficas e respectiva diversificação do perfil das pessoas que vivem sozinhas; pela distribuição territorial dos agregados familiares (sobretudo nas zonas urbanas); e pela própria concepção da vivência em solidão, encarada em muitos casos como uma opção individual ao invés de uma inevitabilidade altamente castradora do quotidiano.

Para concluir a porção do volume que versa sobre a geografia ibérica, Francisco García González apresenta um capítulo dedicado às representações das mulheres solitárias na Espanha rural em perspectiva histórica. No período medieval, os vários modelos de mulheres "marginais" eram contrastados com o arquétipo ideal feminino - a mulher casada com larga prole. Com o avançar do período moderno, sobretudo a partir do século XVIII, as mulheres passaram a ser olhadas como debilitadas e, por conseguinte, cada vez mais dependentes do poder patriarcal. Não obstante, a dicotomia cidade/campo era relevante para o grau de aplicação destas imagens. No ambiente urbano, as conotações negativas da solidão feminina poderiam tender a desaparecer quando as possibilidades económicas e relacionas o permitissem. Ao invés, no campo a ideia de inferioridade física, moral, e intelectual da mulher perpetuava os modelos pré-concebidos.

O capítulo inicial da parte relativa à América Latina, elaborado por Pilar Gonzalbo Aizpuru, analisa a vivência solitária no meio rural mexicano dos últimos trezentos anos. Ao invés da cidade, o solitário não era bem aceite no mundo rural, sentido portanto necessidade de companhia para as suas vivências quotidianas. O impacto desta realidade era particularmente incisivo para as mulheres, cuja busca por um consorte seria incessante. Já para o caso chileno entre 1750 e 1900 (Paulo Alegría Muñoz e Nicolás Celis Valderrama), é notório um grau considerável de celibato feminino - que estaria respectivamente nos 20 e $30 \%$, representando a viuvez entre 12 a 16\%. Para além de ilustrarem a forte dependência feminina relativamente ao consorte, 
os autores interpretam o conceito de uma forma mais polissémica, prestando atenção às características das representações da solidão feminina (aspecto em comum, portanto, com o capítulo de García González).

Os dois capítulos seguintes versam sobre a solidão feminina num espaço bem definido - a província de Córdoba, Argentina. Mónica Ghirardi e Dora Celton questionam o grau de dependência das viúvas relativamente à sociedade patriarcal de finais do Antigo Regime, fazendo uso dos censos de 1778, $1795 \mathrm{e}$ 1813. Sendo o número de viúvas mais elevado na província do que propriamente na cidade, com excepção daquelas com mais de 50 anos, as autoras indicam que a etnia constituía um factor distintivo. A tendência para ostentar a viuvez era mais elevada nas viúvas de sangue espanhol, comparativamente às homólogas de sangue misto. $\mathrm{O}$ facto de muitas destas viúvas não chegarem a consorciar-se novamente deixa antever um grau mínimo de independência face ao controlo social. Conclusões semelhantes são visíveis no capítulo de Claudio Küffer, onde enceta uma abordagem micro à freguesia de Tulumba (Córdoba). Neste espaço de observação, os lares encabeçados por mulheres (no caso das mulheres espanholas, com predominância para as viúvas) não se associariam necessariamente a uma situação de fragilidade e/ou precariedade, mesmo reconhecendo a tónica patriarcal da sociedade.

A etnia é também um dos factores chave da análise efectuada por Maria José Vilalta às mulheres no Páramo andino durante os séculos dezoito e dezanove. Cruzando estes dados com outros indicadores sobre estado civil, idade, profissão, escolaridade, e estrutura familiar, a autora aponta um difícil caminho de sobrevivência - sobretudo para as mulheres indígenas, menos escolarizadas e com menores hipóteses de obter rendimentos favoráveis para enfrentar eventuais situações de solidão. Num capítulo dedicado a Porto Alegre (Brasil) no final do período colonial (por Ana Sílvia Volpi Scott, Jonathan Fachini da Silva, Dario Scott e Denize Teresinha Leal Freitas), as solidariedades entre a vizinhança e outras estratégias estabelecidas pelo poder local - com destaque para a criação de crianças expostas - são enfatizadas enquanto factores de sobrevivência das mulheres celibatárias, independentemente de terem ou não família a seu cargo. Desta forma, as mulheres que chefiavam lares encontrariam forma de se afastarem uma situação de precariedade generalizada, à partida expectável de acordo com alguma historiografia de pendor mais tradicional.

Natalia Carballo Murillo analisa a evolução das mulheres costa-riquenhas cabeças de household (viúvas e solteiras) da província de Puntaneras, tendo em conta as transformações demográficas que decorrem entre 1973 e 2011. Devido a um conjunto de factores que inclui a melhoria de condições de saúde, as mudanças culturais, ou a diminuição da quantidade de filhos por mulher, a autora identifica um incremento do número de solteiras, ao passo que é visível a descida do número de viúvas. Por último, Daniela Alicia Gorosito examina a maternidade celibatária na ruralidade argentina do século XXI. Partindo especificamente dos censos populacionais de 2001 e 2010, Gorosito denota um incremento das mães solteiras em ambiente rural, sobretudo num escalão etário mais jovem (20-24 anos). Tal incremento parece, por outro lado, ser independente do grau de formação que cada mãe solteira possa ter obtido. Ainda assim, a autora traça um quadro de precariedade mais generalizada para as mães solteiras mais jovens e menos instruídas, porventura com menores recursos para enfrentar os desafios de gerir o lar sem apoio do consorte.

Apesar da disparidade de visões e de resultados protagonizada neste volume, coincidente com a elevada abrangência cronológica e geográfica que nele é reunida, uma tendência clara sobressai: a de que as vivências em solidão não implicam necessariamente um quadro generalizado de pobreza, abandono, e marginalização social, contrariamente às representações da solidão - sobretudo, das solitárias no mundo rural - nas sociedades tradicionais (capítulo de García González).

Tendo em conta o enfoque no mundo rural, a distribuição dos casos de estudo por várias partes de Espanha e do mundo sul-americano está bem conseguida. Dada a inclusão de um caso de estudo brasileiro, questiona-se apenas se um homólogo relativo ao interior português não poderia também fazer parte do volume. Tal inclusão seria deveras pertinente, sobretudo dado o potencial migratório no espaço atlântico na longa duração, o que em si constituiria um bom observatório da solidão nas sociedades modernas e contemporâneas. 
Outro ponto menos conseguido a salientar passa pelo parco (ou mesmo pela ausência de) diálogo entre os vários capítulos que compõem o volume. Apesar do recurso à bibliografia especializada minorar até certo ponto esta fragilidade, crê-se que existiriam vantagens na existência no estabelecimento de pontos comparativos entre as várias contribuições; sobretudo dada a similaridade entre cronologia, objecto de análise e, nalguns casos, metodologias de recolha e tratamento de dados.

Em simultâneo, o grande aplauso e a grande crítica a efectuar reside no acentuado pendor em torno da análise de género. $\mathrm{O}$ volume conseguiu transmitir não apenas que eram as mulheres as mais afectadas pelos eventuais efeitos da solidão na longa duração; mas foi efectivamente mais além, questionando que tipo de mulheres eram estas, cruzando para tal informação etária, socioeconómica, demográfica e profissional. Contudo, o volume poderia ser mais ambicioso do ponto de vista da abrangência de género, no sentido de promover um maior confronto com os vários tipos de homens, que, por variadas razões, se viam numa situação similar de solidão. É certo que as sociedades tradicionais discriminariam mais facilmente a solidão feminina e que, como tal, uma reavaliação da solidão masculina é dificultada a vários níveis por tais preconcepções (inclusivamente a nível documental, dado parte dos contributos fazer uso de fontes censitárias dos séculos XVIII e XIX). Ainda assim, crê-se que o fenómeno da solidão só se pode conhecer na plenitude levando a cabo este esforço para os vários tipos de homens, ultrapassando algum dogmatismo associado à imagem do paterfamilias e explorando melhor as margens da sociedade.

Apesar dos pontos acima mencionados, este volume cumpre o propósito de mapear todo um campo de estudos em desenvolvimento, na medida em que confronta o leitor não apenas com um conjunto de contribuições consolidadas por décadas de investigação, mas também com trabalhos marcados por perspectivas inovadoras sobre o fenómeno da solidão. Constituirá, portanto, um volume de referência para investigadores dedicados ao estudo da família, do género, e, geralmente, da história social ibero-americana dos últimos cinco séculos. 